\title{
Tablet for Topical Solution Dosage Form
}

National Cancer Institute

\section{Source}

National Cancer Institute. Tablet for Topical Solution Dosage Form. NCI Thesaurus.

Code C149980.

Solid, usually single-dose preparation consisting of a tablet, usually uncoated, intended to be dissolved in the specified liquid to obtain a cutaneous solution. 